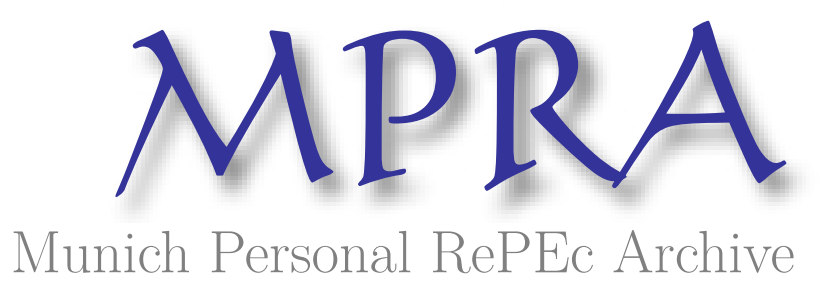

\title{
A Threshold Cointegration Analysis of Asymmetric Adjustment of OPEC and non-OPEC Monthly Crude Oil Prices
}

Ghassan, Hassan B. and Banerjee, Prashanta K.

13 October 2013

Online at https://mpra.ub.uni-muenchen.de/62168/

MPRA Paper No. 62168, posted 16 Feb 2015 15:48 UTC 


\title{
A Threshold Cointegration Analysis of Asymmetric Adjustment of OPEC and non-OPEC Monthly Crude Oil Prices
}

\author{
Hassan Belkacem Ghassan \\ Department of Economics \\ Umm Al-Qura University, Saudi Arabia
}

\author{
Prashanta Kumar Banerjee \\ Department of Research, Development \& Consultancy \\ Institute of Bank Management, Bangladesh
}

\begin{abstract}
The purpose of this paper is to analyze the dynamics of crude oil prices of OPEC and non-OPEC countries using threshold cointegration. To capture the long run asymmetric price transmission mechanism, we develop an error correction model within a threshold cointegration and CGARCH errors framework. The empirical contribution of our paper specifies the cointegrating relation between OPEC price and non-OPEC prices and estimates how and to what extent the respective prices adjust to eliminate disequilibrium. The finding exhibits that the conditional volatility of variance has long run memory feature and the shocks on the long run component do not adjust quickly. The OPEC producers could not drive down (up) crude oil prices with equivalent speeds for all participants in the market. The slow adjustment of OPEC process of positive discrepancies to the long run equilibrium indicates that OPEC does not prefer modest oil prices. While, the rapid adjustment of non-OPEC process signifies their preference of modest oil prices after oil price increases. These differences of speeds show evidence for competitive behaviors between OPEC and non-OPEC countries.
\end{abstract}

Key words: Asymmetric adjustment, CGARCH, OPEC prices.

JEL Classification: Q40, E30, C51, C22 


\section{Introduction}

Oil is one of the world's largest traded commodity, most of the international flow of funds moves around this commodity. And everybody is far more aware of changes in its price. Therefore, the price of oil is always under public scrutiny. The price was stable near \$3 per barrel before 1970. Afterwards, the Arab oil embargo, the crises in Iran and Iraq, the recent crises in the Middle East and, importantly, the increasing demand of growing economies like China, India have impacted on the prices of oil, which reached a record level of $\$ 145$ per barrel in 2008. Changes in the price of oil are overwhelmingly significant because it drives national and international economic and military policies around the world. Therefore, the analyses of the price of oil always have been significant interest to academics, bankers, business people and policy makers alike.

The Organization of Petroleum Exporting Countries (OPEC), which was established in 1960, and often treated as a monopoly and a cartel, has had mixed success in controlling prices. OPEC might exercise great influence over the world prices of oil, because the member countries have enough spare capacity of oil. The non-OPEC countries have an excess demand of approximately 33 million barrels per day (Appendix Table A), even though their share is as high as 60 per cent in the total world production of oil (Appendix Table B). This entire excess demand of non-OPEC countries is satisfied with the oil supplied by the OPEC countries only. As a result, it is a common belief that the non-OPEC countries behave as price takers and the OPEC might play a dominant role in the world by setting the price of oil by adjusting its production.

A large body of literature is available on the price of oil. Gately (1993) examines the price reversibility of world oil demand using price decomposition methods. He finds that the reductions in the world demand for oil following the oil price increases of the 1970s have not been completely reversed by the price cuts of the 1980 s. The response to price cuts in the 1980 s equates to only one -fifth of the total price increases in the 1970s. De Santis (2003) seeks to explain the crude oil prices fluctuations by focusing on the quota regime as a main characteristic adopted by the OPEC agreements. De Santis 
observes that Saudi Arabia's behavior is asymmetric in response to the world demand shocks because they have an incentive (disincentive) to intervene if negative (positive) demand shock hits the crude oil market. Jones (1990) studies OPEC behavior under falling prices and shows evidence of oil price reductions being more the result of deliberate output adjustments by the cartel, not of an unintentional outcome of a breakdown in cartel discipline that may eventually cause its collapse. Lin (2009) finds an oligopolistic behavior among non-OPEC producers and collusion among OPEC producers during the period 1970-2004. In addition, Hamilton (2008) examines the factors responsible for changes in crude oil prices by reviewing the statistical behavior of oil prices, relating them to the predictions of theory, and investigates in details the key features of petroleum demand and supply. He concludes that although scarcity rent made a negligible contribution to the price of oil in 1997 , it could begin to play a role. Li (2010) shows that the flow of causation runs from non-OPEC production to the world oil prices and then to OPEC production. This is a complete reversal of what one would expect if OPEC were influential in the world oil market. This indicates that it is not appropriate to treat OPEC as a dominant firm. Apart from these, many empirical studies are conducted on supply and demand in the petroleum market (see e.g., Adelman 1962; Kennedy 1974; Berndt \& Wood 1975; Hausman 1975; Nordhaus 1980; Gately 1984; Griffin 1985; Goldberger 1991; Manski 1995; Angrist et al. 2000; Gately \& Huntington 2002; Lin 2009).

Most of the previous work assumes that the adjustment process is strictly symmetric. Now, it is widely acknowledged that many important economic variables display asymmetric adjustment paths. Moreover, a number of studies claim that there is an asymmetric relationship between the oil price followed by OPEC and non-OPEC countries (Ewing et al. 2006; Bekiros et al. 2008; Kang et al. 2009; Mohammadi et al. 2010; Hammoudeh et al. 2010). Chen et al. (2005) documented new supportive evidence for asymmetric adjustment in the United States retail gasoline prices. However, the local market price is a different story because it is affected by the sales tax and domestic oil reserves, especially within the United States. The asymmetric transmission is found to occur not just through the spot markets of crude oil and refinery gasoline, but also through their future markets. It also shows that the observed asymmetry in the price transmission primarily occurs downstream - not upstream- of the transmission 
process. Lastly, Balke et al. (1998) use several different model specifications to analyze the relationship between the oil prices and the spot, wholesale, and retail prices of gasoline. They find asymmetry is sensitive to model specification, but is pervasive in the most general model. A number of empirical studies have also been conducted on price asymmetry for North American markets, but the findings of these studies are mixed (Borenstein et al. 1997; EIA 1999; Godby et al. 2000).

The purpose of this paper is to analyze the dynamics of oil prices of OPEC and non-OPEC countries in the international market. The aim is to reveal whether the prices of oil for both groups are cointegrated, either the price adjustment process is symmetric or asymmetric, and to determine whether any causality relationship exists among the two different oil prices. Given the perception that exists regarding the oligopolistic nature of the oil market, the paper aims to test for the presence of cointegration in the presence of the asymmetric error correction across the oil prices followed by OPEC and non-OPEC countries. The correspondence between error correction models, which represents cointegrating relationships and autoregressive models of an error term, allows us to apply the method suggested by Enders and Siklos (2001). Hence, the threshold autoregressive (TAR) and momentum-threshold autoregressive (MTAR) method of adjustment are followed here.

The paper is organized as follows: Section 2 describes the methodology used, Section 3 reports the description of the data and the empirical findings, and Section 4 concludes.

\section{Methodology}

First, the Engle and Granger (1987) two-step method is employed to test cointegration between the oil prices of OPEC and non-OPEC countries. The price of oil of the OPEC and non-OPEC countries is represented by $p_{1}$ and $p_{2}$, respectively. This entails using ordinary least squares to estimate the long-run relationship, which is given by the following:

$$
p_{1 t}=\alpha+\beta p_{2 t}+\varepsilon_{t}
$$


After obtaining the estimated residuals from the equation 1, the ADF test is used on the resulting residuals, $\hat{\varepsilon}_{t}$, to illustrate the cointegrated relationship between these two variables. This is illustrated by the following equation:

$$
\Delta \hat{\varepsilon}_{t}=\rho \hat{\varepsilon}_{t-1}+u_{t}
$$

where $u_{t}$ is a white noise error term. If the residuals retrieved from the equation (1) is stationary, then the null hypothesis of no cointegration is rejected. However, Enders and Siklos (2001) argue that the test for cointegration and its extensions are mis-specified if adjustment is asymmetric. They proposed the following asymmetric adjustment, called the threshold autoregressive (TAR) model:

$$
\Delta \hat{\varepsilon}_{t}=\rho_{1} I_{t} \hat{\varepsilon}_{t-1}+\rho_{2}\left(1-I_{t}\right) \hat{\varepsilon}_{t-1}+u_{t}
$$

where $\rho_{1}$ and $\rho_{2}$ are the speed-adjustment coefficients and $I_{t}$ is the indicator function, which is defined as the following:

$$
I_{t}=\left\{\begin{array}{lll}
1 & \text { if } & \hat{\varepsilon}_{t-1} \geq \tau \\
0 & \text { if } & \hat{\varepsilon}_{t-1}<\tau
\end{array}\right.
$$

This indicator function indicates that $\rho_{1}$ signifies adjustments from below the threshold $\tau$ (widening), because the residual is expanding or greater than the threshold. The opposite holds true for $\rho_{2}$ : the adjustment is from above the threshold or the spread is narrowing.

This specification allows for asymmetric adjustment. If the system is convergent, then the long-run equilibrium value of the sequence is given by $\tau$ which can be $0 .{ }^{1}$ The sufficient conditions for the stationarity of $\hat{\varepsilon}_{t}$ are $\rho_{1}<0, \rho_{2}<0$ and $\left(1+\rho_{1}\right)\left(1+\rho_{2}\right)<1$ (Petrucelli and Woolford 1984). In this case, if $\hat{\varepsilon}_{t-1}$ is above its long-run equilibrium value, then adjustment is at the rate $\rho_{1}$, and if $\hat{\varepsilon}_{t-1}$ is below long-run equilibrium, then the adjustment is at the rate $\rho_{2}$. This adjustment would be symmetric if $\rho_{1}=\rho_{2}$. However, if the null hypothesis $\mathrm{H}_{\mathrm{o}}: \rho_{1}=\rho_{2}$ is rejected, then using the TAR model, we can capture the signs of asymmetry. For example if $-1<\rho_{1}<\rho_{2}<0$, then the negative phase of the $\hat{\varepsilon}_{t}$

\footnotetext{
${ }^{1}$ According to Enders and Siklos (2001), it is not necessary that the threshold coincides with the attractor. Then the appropriate estimate of $\tau$ yields the lowest residual sum of squares.
} 
series will tend to be more persistent than the positive phase. ${ }^{i}$ In the above case, it is necessary to estimate the threshold value that will be equal to the cointegrating vector. A method of searching for a consistent estimate of the threshold was undertaken by using a method proposed by Chan (1993).

Enders and Siklos (2001) suggest a further alternative such that the threshold $\gamma$ depends on the previous periods change in $\hat{\varepsilon}_{t}$ instead on the level of $\hat{\varepsilon}_{t}$. In this case, the indicator can be set as follows:

$$
I_{t}= \begin{cases}1 & \text { if } \Delta \hat{\varepsilon}_{t-1} \geq \gamma \\ 0 & \text { if } \Delta \hat{\varepsilon}_{t-1}<\gamma\end{cases}
$$

The series $\hat{\varepsilon}_{t}$ exhibits more momentum in one direction than the other. The model given by (3) along with the equation (5) depicts the momentum threshold auto regression (MTAR) model. The MTAR can be used to capture different types of asymmetry. For example, if $\left|\rho_{1}\right|<\left|\rho_{2}\right|$, then the MTAR exhibits little adjustment for positive $\Delta \hat{\varepsilon}_{t-1}$, but substantial decay for negative $\Delta \hat{\varepsilon}_{t-1}$. In other words, increases tend to persist, but decreases tend to revert quickly back to the attractor irrespective of where disequilibrium is relative to the attractor. As before, the threshold for this model is estimated using Chan's methodology.

In this test, to implement the case of the TAR or MTAR adjustment, the indicator function is set according to Eq. (4) or Eq. (5), respectively, and the estimate of Eq. (3) accordingly. The $\phi$-statistic for the null hypothesis of non-stationarity of $\hat{\varepsilon}_{t}$, i.e. under $\mathrm{H}_{\mathrm{o}}: \rho_{1}=\rho_{2}=0,\left\{\hat{\varepsilon}_{t}\right\}$ has a unit root. The value of the $\phi$-statistic is compared to the critical values computed by Enders and Granger (1998). If we can reject the null hypothesis, it is possible to test for asymmetric adjustment because $\rho_{1}$ and $\rho_{2}$ converge to a multivariate normal distribution (Tong 1990). The $\mathcal{F}$-statistic is used to test for the null hypothesis of symmetric adjustment, that is, $\mathrm{H}_{\mathrm{o}}: \rho_{1}=\rho_{2}$. Diagnostic checking of the residuals are undertaken to ascertain whether the $u_{t}$ series has auto-correlation process using the Durbin-Watson test.

The finding of cointegration with threshold adjustment justifies the estimation of the following error correction model with a threshold adjustment. The error correction model with a threshold cointegration, which assumes long-run asymmetric adjustments, can be written as the following: 


$$
\Delta p_{1 t}=\alpha+\mu_{1} e c t_{t-1}^{+}+\mu_{2} e c t_{t-1}^{-}+\sum_{\mathrm{i}=1}^{\mathrm{p}} \beta_{i} \Delta p_{1 t-i}+\sum_{j=0}^{q} \beta_{j} \Delta p_{2 t-j}+v_{t}
$$

where the variables $e c t_{t-1}^{+}=I_{t} \hat{\varepsilon}_{t-1}$ and $e c t_{t-1}^{-}=\left(1-I_{t}\right) \hat{\varepsilon}_{t-1}$ represent the error correction terms, defined from the indicator functions $I_{t}$ in Eq. (4) and (5). ${ }^{2}$ The coefficient $\mu_{\mathrm{i}}$ captures the speed of adjustment or rate of convergence from gravitates back toward the long-run equilibrium path. In case of $e c t_{t-1}^{-}$i.e. undervaluation of the current crude oil prices, we expect that $\mu_{1}$ would be negative, therefore leading to a downward adjustment. In case of $e c t_{t-1}^{+}$i.e. overvaluation, we expect that $\mu_{2}$ would be negative, which conducts to an upward adjustment to converge to the long-run equilibrium. If the convergence condition is verified i.e. $\left|\mu_{i}\right|<1$, when $\mu_{1}>0\left(\mu_{2}>0\right)$, we will have an upward (downward) adjustment. The stochastic error $v_{\mathrm{t}}$ is supposed to be distributed following the specific component GARCH (CGARCH) errors Eq. (7), which are used particularly in financial applications (Gospodinov 2008). This framework, named ECM-TAR-CGARCH, leads to a parsimonious representation of some stylized features of the OPEC and non-OPEC prices such as the time-varying volatility and the volatility clustering. The lag numbers are determined using the information criteria such AIC and T-sig. The structure of errors is determined by the following equations:

$$
\begin{aligned}
& v_{t}=\sqrt{\sigma_{t}^{2}} \xi_{t}=\sqrt{q_{t}+s_{t}} \xi_{t} \quad v_{t} \mid \Omega_{\mathrm{t}-1} \sim \text { i.i.d. }\left(0 ; \sigma_{\mathrm{t}}\right) \text { and } \xi_{\mathrm{t} \sim \text { i.i.d. }(0 ; 1)} \\
& \sigma_{t}^{2}-q_{t} \equiv s_{t}=\alpha\left(\varepsilon_{t-1}^{2}-q_{t-1}\right)+\beta\left(\sigma_{t-1}^{2}-q_{t-1}\right) \\
& q_{t}=\omega_{0}+\rho\left(q_{t-1}-\omega_{0}\right)+\varphi\left(\varepsilon_{t-1}^{2}-\sigma_{t-1}^{2}\right)
\end{aligned}
$$

where $\xi_{t}$ is a stochastic process of the independently and identically distributed error term. The Eq. (8) of the conditional variance $\sigma_{t}^{2}$ exhibits the long-run component $q_{t}$ and the short-run component $\left(\sigma_{t}^{2}-q_{t}\right)$. This transitory component $s_{t}$ contains the discrepancies around the long run component. Engle and Lee (1999) point out that the CGARCH process, defined in separated equations (8) and (9), is weakly stationary if $\rho<1$ and $\alpha+\beta<1$. $^{3}$ The CGARCH model captures the volatility persistence of the

\footnotetext{
${ }^{2}$ In the TAR adjustment, we have $I_{t} \hat{\varepsilon}_{t-1}=I_{t}\left(\hat{\varepsilon}_{t-1} \geq \tau\right)$ and $\left(1-I_{t}\right) \hat{\varepsilon}_{t-1}=I_{t}\left(\hat{\varepsilon}_{t-1}<\tau\right)$; while in the MTAR adjustment: $I_{t} \hat{\varepsilon}_{t-1}=I_{t}\left(\Delta \hat{\varepsilon}_{t-1} \geq \gamma\right)$ and $\left(1-I_{t}\right) \hat{\varepsilon}_{t-1}=I_{t}\left(\Delta \hat{\varepsilon}_{t-1}<\gamma\right)$.

${ }_{3}^{3}$ Combining the transitory and permanent equations, the model reduces to a non-linearly restricted CGARCH $(2,2)$.
} 
transitory and permanent dynamics. The long run trend of the conditional variance indicates the idea of time-varying long run volatility. The parameter $\rho$ represents the decay rate and specifies the speed of the mean reversion, which assumes that the high and lower crude oil prices are temporary. Therefore, it is expected that the high and lower deviations, due to diverse shocks in the prices, will go back to an average price. The conditional variance displays the long run mean reversion to a constant level given by the unconditional variance $\omega_{0}$. The volatility prediction error $\left(\varepsilon_{t-1}^{2}-\sigma_{t-1}^{2}\right)$ has zero-mean and serially uncorrelated; it drives the dynamics of the permanent component (Poon et al. 2006). The strength of shocks to the permanent component is defined by $\frac{\partial q_{t}}{\partial \varepsilon_{t-1}^{2}}=\varphi$. The shocks to the transitory component revert to the trend $q_{t}$, while in the GARCH model the shocks decay to the unconditional variance $\omega_{0} \equiv \sigma^{2}$. The power of shocks to the transitory component is determined by $\frac{\partial\left(\sigma_{t}^{2}-q_{t}\right)}{\partial \varepsilon_{t-1}^{2}}=\alpha$. The permanent process $q_{t}$ has memory close to unit root when $\rho$ is close to $1 .^{4}$ Typically $\rho$ is between 0.9 and 1 (Table 4), then $q_{t}$ tends to its unconditional variance $\omega_{0}$ very slowly, this is due to the slow adaptation to news. If $(\alpha+\beta)<1$, the transitory mean reverting process $s_{t}$ has more rapid time decay governed by $(\alpha+\beta)$. If $\rho<1$ the conditional variance $\sigma_{t}^{2}$ mean-reverts to a long-run trend level $q_{t}$ with the speed determined by $\rho$. It is assumed that when $0<\alpha+\beta<\rho<1$, then the permanent component is more persistent than the transitory component. The persistence in the transitory component is lower than the persistence in the permanent component, because $(\alpha+\beta)<\rho$. Consequently, the permanent component $q_{t}$ has a long memory, whereas the transitory component has a short memory (Ray and Tsay 2000).

The volatility persistence of transitory large shocks is shorter than shocks due to habitual news events, but it remains that the large shocks could have a permanent impact. Albeit with the CGARCH structure, the parameters do not have all non-negative signs. The transitory component could be negative, without the conditional variance becoming negative, suggesting the shocks on the volatility during the convergence of the long-run trend. These volatility shocks lead to an uncertain future evolution,

\footnotetext{
${ }^{4}$ The original CGARCH model defines the permanent component as a unit root process $(\rho=1)$. However, Engle and Lee (1999) extend the model to a general specification allowing the permanent component to be a non-unit root process.
} 
indicating the presence of the volatility clustering (Engle and Patton 2000), which means that when the negative news happens during the prices increase, the volatility also increases. ${ }^{5}$

In the component GARCH model, which is designed to capture the long memory of volatility, a shock in the volatility series appears to have a long memory, and impacts on future volatility over a long temporal horizon. When the autoregressive root $\rho=1{ }^{6}$ the unconditional variance does not exist i.e. there is no mean reversion, but a shock remains through conditional variance and impacts upon future volatility over an infinite horizon (Bollerslev and Engle 1993). The CGARCH process is covariance stationary, when the conditional variance is stationary; and then both the permanent and transitory components must both be covariance stationary, which necessitates $\alpha+\beta<1$ and $\rho<1$ (Engle and Lee 1999).

\section{Data and Empirical Results}

The study is based on the monthly data on the per barrel price of crude oil in US Dollar in both OPEC and non-OPEC countries. Both variables are converted into natural logs, and these variables are given a new name: LOPEC and LNOPEC. The averages of OPEC and non-OPEC prices are based on the affiliations of the countries for the stated period of time that may differ from current affiliations. The monthly data are based on FOB prices from the first business day of the first week. OPEC and non-OPEC prices are calculated as the average price (FOB) weighted by the export volume. To avoid the structural changes that occurred during the 1970s and 1980s, our sample monthly data (Appendix, Figures 1) cover the period January 1997 through April 2011. The data are gleaned from US Energy Information Administration and the link used for collecting these data is as follows: http://www.eia.gov/dnav/pet/pet_pri_wco_k_w.htm.

\footnotetext{
${ }^{5}$ This phenomenon appears when the differences in the interpretability of information from the crude oil market accentuate the competitiveness between the OPEC and non-OPEC producers.

${ }^{6}$ When the volatility of a long run process is I(1) i.e. $\rho=1$, then the conditional variance contains a unit root and the persistence of shocks is infinite. The Wald test for the null hypothesis $\rho=1$ shows (Table 4 ) that the unit root is strongly rejected for models 1-2, and accepted for models 3-4. The LM-Arch and Ljung-Box tests reject the null hypotheses of Arch effect and the autocorrelation in the residuals (Table 4b). Then, we should have correct estimates of the standards errors which validate the statistical tests.
} 
The mean to median ratio of each variable (Table 1) apparently indicates that the distribution of the variable is not far from a symmetrical distribution as this ratio is close to one ${ }^{7}$. We expect that the crude oil prices do not follow an independent and identically distribution. If the random variables are independent, then the unconditional distribution is equal to the conditional distribution. But, the temporal dependence doesn't allow the independence feature even in the normal distribution, it makes more interesting for the conditional distribution. Then, the empirical analysis is focused on the unconditional distribution of the crude oil prices, based on past information and requiring stable processes. However, the standard deviation, skewness and kurtosis fail to confirm the normality of each variable. The distribution of monthly data of crude oil prices exhibits a positive skewness and a positive excess kurtosis; it appears that we have a leptokurtic distribution. The Jarque-Bera statistics, as parametric test, clearly reject the null hypothesis of a normal distribution.

Table 1: Descriptive Statistics and Unit Root Tests

\begin{tabular}{|l|c|c|}
\hline & LOPEC & LNOPEC \\
\hline Mean & 3.573 & 3.569 \\
\hline Median & 3.410 & 3.441 \\
\hline Std. Dev. & 0.659 & 0.652 \\
\hline Skewness & 0.015 & 0.007 \\
\hline Kurtosis & 1.965 & 2.015 \\
\hline Jarque-Bera (p-value) & $7.688(0.021)$ & $6.950(0.031)$ \\
\hline ADF [Critical at 1\%] & $-3.626[-4.013]$ & $-3.242[-4.013]$ \\
\hline ADF-GLS [Critical at 1\%] & $-2.341[-3.496]$ & $-2.009[-3.495]$ \\
\hline
\end{tabular}

To determine the order of integration, both oil prices were initially tested by using the ADF and ADFGLS with traditional and Modified AIC and SIC. The Modified AIC, suggested by Ng and Perron (2001), improves the size and power of the test. These statistics suggest that the OPEC and non-OPEC prices

\footnotetext{
${ }^{7}$ Using the nonparametric test statistics in the one-sample test framework, as Wilcoxon signed ranks and Van Der Waerden normal scores tests, for testing the null hypothesis of the equality of median to mean, we accept the alternative hypothesis. Consequently, the distribution of logged prices of OPEC and non-OPEC cannot be normally distributed. In addition, to check if the underlying data are normally distributed, we use the Quantiles-plot. The results indicate that the QQ-plots do not lie on a straight line, because the two distributions for each series deviate from linearity pattern and visually there are fat tails.
} 
have unit root process, but are stationary in their first difference term. In addition, when the variables are I(1), the unconditional distribution may not exist. Of course, the underlying stochastic process cannot lead to the leptokurtic unconditional distribution if the process is not strictly stationary. Plots of the first difference of the logged crude oil prices (Appendix, Figures 1) exhibits a conditional heteroscedasticity, but it does not mean necessarily that the series are from leptokurtic conditional distribution. So, the unconditional leptokurtosis could reflect conditional heteroscedasticity. A GARCH model may be enough for this purpose to capture the fat-tailedness of the unconditional distribution (Diebold \& Lopez 1995, Engle \& Gonzalez-Rivera 1991). The movement of non-OPEC prices does not occur in isolation, but they cluster with OPEC prices. The presence of the volatility clustering would justify to model in the CGARCH framework (Engle and Patton 2000). ${ }^{8}$

\subsection{Cointegration tests}

To determine the long-run equilibrium relation between OPEC price and non-OPEC prices, both Engle and Granger's (EG, 1987) and Perron and Rodriguez's (PR, 2001) methods have been implemented using the software GAUSS. Both tests assume only a symmetric adjustment. Because the visual data do support a constant and trend, each cointegration test includes a constant and trend as deterministic components. For the estimation of the EG, the AIC and T-significance are used to choose the lag order. The results in Table 2 show that the EG test rejects the null hypothesis of no cointegration at the $5 \%$ and $1 \%$ level, respectively, in accordance with the AIC and T-significance criteria. This illustrates that there is a plausible cointegration relationship between the oil-selling price determined and followed by OPEC and non-OPEC countries. Additionally, the PR test supports the findings of the EG test and rejects the null hypothesis of no cointegration at the $1 \%$ level for both the AIC and T-significance criteria.

\footnotetext{
${ }^{8}$ Both of the properties of conditionally leptokurtic and conditionally heteroscedastic might be combined in a single model like a regime switching model or multivariate distribution using mixed-normal conditional distributions (Holton 2014, Alexander \& Lazar 2006). These ways will be explored in our next research paper and require further study.
} 
Table 2a: Cointegration Tests (Dependent Variable LOPEC) ${ }^{\mathrm{ii}}$

\begin{tabular}{|c|c|c|c|c|}
\hline & \multicolumn{2}{|c|}{ EG } & \multicolumn{2}{c|}{$\mathrm{PR}=\mathrm{EG}^{\mathrm{GLS}}$} \\
\hline & AIC & T-Sig & MAIC & T-Sig \\
\hline$\rho$ & -0.499 & -0.855 & -0.396 & -0.742 \\
\hline$\tau_{\rho}$ & $(-3.954)$ & $(-5.477)$ & $(-3.789)$ & $(-4.946)$ \\
\hline
\end{tabular}

Table 2b: Cointegration Tests (Dependent Variable LNOPEC)

\begin{tabular}{|c|c|c|c|c|}
\hline & \multicolumn{2}{|c|}{ EG } & \multicolumn{2}{c|}{$\mathrm{PR}=\mathrm{EG}^{\mathrm{GLS}}$} \\
\hline & AIC & T-Sig & MAIC & T-Sig \\
\hline$\rho$ & -0.437 & -0.875 & -0.412 & -0.797 \\
\hline$\tau_{\rho}$ & $(-5.123)$ & $(-5.535)$ & $(-3.891)$ & $(-5.122)$ \\
\hline
\end{tabular}

In the EG method, if the variables are interchangeable and the sample size is sufficient, then the same results will be attained (Table 2a and Table 2b). According to Horvath \& Watson (1995) when there is only one cointegrating vector, simple univariate tests provide an alternative to the likelihood-based tests. They conclude that the power trade-off between the multivariate and the univariate tests for cointegration is more interesting in higher dimensional systems.

In our case, the Johansen test justifies that the logged price series of OPEC and non-OPEC move together towards a one stable long run relationship. ${ }^{9}$ We find a significant trace-statistic with 26.96 and a significant max-eigen statistic with 26.06, the critical values at $1 \%$ are 19.94 and 18.52 , respectively. By running the causality test, from VEC model instead of VAR model, using $\chi^{2}$-statistic, we find a causality from OPEC prices to non-OPEC prices, where $\chi^{2}=4.95$ with p-value equal 0.084 .

The statistic $q_{f}$ of Stock \& Watson (1988) tests the null hypothesis of stochastic trends of series against their common trends i.e. cointegrated series ${ }^{10}$ in the multivariate setting. The test is based on filtering the data and using VAR representation. Testing for two versus one common trends using $q_{f}(2,1)$ statistic, the reported test by Gauss program of Camacho leads to $q_{f}=-92.88$ which is more

\footnotetext{
${ }^{9}$ When the cointegrating vector is unique, the EG method is validated. But, when the cointegrating vector is not unique, we could work with VEC model.

${ }^{10}$ They indicate that if each of $n$ series is $\mathrm{I}(1)$, but can be jointly characterized by $k<n$ stochastic trends, then the vector representation of these series has $k$ unit roots and $(n-k)$ distinct stationary linear combinations i.e. cointegrating vectors.
} 
negative than the critical value -92.88 at $1 \%$ level (Table 2 in Stock \&Watson 1988). Then, we reject the null hypothesis in favor of a model in which the two crude oil prices contain a single common trend.

The Johansen procedure is a vector cointegration test method using sequential tests for determining the number of cointegrating vectors. This method has the advantage over Engle-Granger (EG) cointegration test in that it can estimate more than one cointegration relationship, if the data set contains two or more time series. But, the interpretation of the results becomes difficult, when there are multiple cointegrating vectors. It is also invariant to the selection of the variable for normalization, whereas in the EG procedure the results depend on how the single long-run equation is specified. In some cases, based on economic theory, it is possible to identify which variable is the dependent variable on the left side of the equation. But, the Johansen method often leads to a cointegrating vector without economic meaningful (Hatanaka 1996).

The limitation of the Johansen procedure is that it assumes that the cointegrating vector remains constant during the sample period, which is not true owing to the technological progress, change in people's preference, economic crisis, policy or regime alteration and institutional development. Such limitations are also valid for the EG method. Therefore, the threshold cointegration would be more appropriate for the crude oil prices processes.

Afterwards, the residuals of model (1) are estimated by following the TAR and MTAR models in which the lag order is chosen by using the AIC and T-significance tests. Considering the TAR model with AIC, the point estimates are calculated to be $\rho_{1}=-0.305$ and $\rho_{2}=-0.582$, and they have the correct signs for convergence (Table 3A). The statistic $\phi=18.575$ is greater than the $1 \%$ critical value. It implies that the null hypothesis of $\rho_{1}=\rho_{2}=0$ can therefore be soundly rejected, indicating that the series are cointegrated. After confirming cointegration between the oil prices of OPEC and non-OPEC countries, the null hypothesis of no asymmetry $\left(\rho_{1}=\rho_{2}\right)$ can be tested by using the standard $\mathcal{F}$ distribution (Enders and Granger 1998). The sample value of $\mathcal{F}=4.403$ with p-value of 0.037 implies that we can also reject the null hypothesis and find the evidence of the asymmetric adjustment. The TAR 
model following T-significance test for lag selection also completely supports these findings. Therefore, we can conclude that according to the TAR test, oil prices followed by OPEC and non-OPEC countries are cointegrated and that the asymmetry is found to exist. The crude oil market prices of OPEC and nonOPEC have a high asymmetric-cointegration, which may be related to the easy flow of oil market prices information. The asymmetry feature could be used to stabilize the crude oil prices at an acceptable level from an increase or a decrease in the main place of the crude oil market.

Table 3A: Threshold Cointegration Tests (Dependent Variable LOPEC) ${ }^{\text {iii }}$

\begin{tabular}{|c|c|c|c|c|c|c|}
\hline & & $\rho_{1}$ & $\rho_{2}$ & $\phi$ & $\mathcal{F}(\mathrm{P}$-value $)$ & $\tau, \gamma$ \\
\hline \multirow{2}{*}{ TAR } & AIC & $-0.305(-3.056)$ & $-0.582(-5.668)$ & $18.575^{* *}$ & $4.403(0.037)$ & -0.0258 \\
\cline { 2 - 7 } & T-Sig. & $-0.331(-2.422)$ & $-0.601(-4.734)$ & $11.230^{* *}$ & $3.961(0.048)$ & -0.0258 \\
\hline \multirow{2}{*}{ MTAR } & AIC & $-0.303(-3.472)$ & $-0.731(-6.081)$ & $21.763^{* *}$ & $9.757(0.002)$ & -0.0251 \\
\cline { 2 - 7 } & T-Sig. & $-0.310(-2.468)$ & $-0.719(-5.272)$ & $13.909^{* *}$ & $8.754(0.004)$ & -0.0123 \\
\hline
\end{tabular}

Table 3B: Threshold Cointegration Tests (Dependent Variable LNOPEC)

\begin{tabular}{|c|c|c|c|c|c|c|}
\hline & & $\rho_{1}$ & $\rho_{2}$ & $\phi$ & $\mathcal{F}($ P-value $)$ & $\tau, \gamma$ \\
\hline \multirow{2}{*}{ TAR } & AIC & $-0.599(-5.788)$ & $-0.298(-3.016)$ & $19.132^{* *}$ & $5.215(0.024)$ & +0.0215 \\
\cline { 2 - 7 } & T-Sig. & $-0.622(-4.835)$ & $-0.336(-2.477)$ & $11.716^{* *}$ & $4.427(0.037)$ & +0.0226 \\
\hline \multirow{2}{*}{ MTAR } & AIC & $-0.673(-6.297)$ & $-0.268(-2.848)$ & $21.681^{* *}$ & $9.492(0.002)$ & +0.0117 \\
\cline { 2 - 7 } & T-Sig. & $-0.732(-5.309)$ & $-0.323(-2.569)$ & $14.118^{* *}$ & $8.714(0.004)$ & +0.0133 \\
\hline
\end{tabular}

Turning to the MTAR and using AIC (Table 3A), the point estimates are found to be $\rho_{1}=-0.303$ and $\rho_{2}=-0.731$, which have the correct signs and suggest convergence. The statistic $\phi$ of 21.763 clearly rejects the null hypothesis of no cointegration at $1 \%$ significance level. Given that the $\mathcal{F}$ value equals 9.757 with P-value of 0.002 , we can reject the null hypothesis of symmetric adjustment. In fact, the evidence of asymmetric adjustment is further enhanced with the MTAR model. Table 3B also indicates almost identical results.

Therefore, the asymmetric adjustment is found both in the TAR and MTAR models under the AIC and T-significance. The point estimates of $\rho_{1}$ and $\rho_{2}$ are found to be negative, which suggest convergence in both the TAR and MTAR models. Because $\left|\rho_{1}\right|<\left|\rho_{2}\right|$, the results exhibit little adjustment for a 
positive $\varepsilon_{\mathrm{t}-1}$ and $\Delta \varepsilon_{\mathrm{t}-1}$ as compared to the substantial decay for a negative $\varepsilon_{\mathrm{t}-1}$ and $\Delta \varepsilon_{\mathrm{t}-1}$. In other words, increases are persistent and tend to revert back to the attractor less rapidly, but decreases tend to revert quickly back to the attractor i.e. long-run equilibrium. Thus, the results show that both the TAR and MTAR models show that there are asymmetric adjustments in oil prices between OPEC and non-OPEC countries. Furthermore, it is confirmed from Tables $3 \mathrm{~A}$ and $3 \mathrm{~B}$ that the adjustment process is not persistent toward equilibrium above the threshold for both the TAR and MTAR models. However, the deviations from equilibrium are almost quickly eliminated when they are below the threshold parameter. This means that the long-run equilibrium relation below the threshold parameter between the oil price of OPEC and non-OPEC countries is more stable with an asymmetric adjustment. This asymmetric adjustment implies some asymmetries between changes in the price of oil for OPEC countries versus the non-OPEC oil price shocks and vice versa.

\subsection{Error correction model}

Given the findings of cointegration between the two oil prices, it is possible to estimate the asymmetric error correction model with the threshold adjustment. The results for the ECM are reported in Table 4. Interestingly, both the TAR and MTAR models detect asymmetry in the oil price adjustment of OPEC and non-OPEC countries. The MTAR model, which has a consistent estimate of the threshold, yields the lowest AIC relative to the other models and the MTAR specification exhibits greater power over the TAR specification (Enders \& Granger 1998). The asymmetric ECM based on the TAR and MTAR specifications with Eq. (6) and specified errors framework Eq. (7-9) replaces the single symmetric ECM.

Through the comparison between the transitory volatility persistence rate $(\alpha+\beta)$ and the permanent decay rate $\rho$, the results of the ECM-Threshold-CGARCH model show that the short run volatilities are less persistent than the long run volatilities. ${ }^{\text {iv }}$ However, these volatilities converge to the mean reversion $\omega_{0}$ at speed $\rho$ after occurrence of the shocks, because $0.9<\rho<1$. Thus, $\mathrm{q}_{\mathrm{t}}$ would move slowly toward the unconditional variance. This means that the shocks on the long run component do not decay quickly, as that the conditional volatility has long run memory feature. The decay rate of the permanent 
component $\rho$ (Figures 3) is estimated for the OPEC prices at a high rate of $99.2 \%$ using the Student's error distribution and $94.1 \%$ using Gaussian error distribution (GED).Therefore, these decay rates imply that approximately $93.8 \%$ i.e. $\rho^{8}=0.992^{8}$ of a shock remains even after 8 trading months and $61.5 \%$ of the shock stays using Student's and Gaussian error distribution, respectively. For the non-OPEC prices, the decay rate $\rho$ is also high at $98.9 \%$ when we use the GED and $97.8 \%$ using normal distribution. Hence $91.5 \%$ and $83.7 \%$ of the effect of the shocks remains even after 8 months using either the GED and normal distribution, respectively (Appendix, Figures 2). Using the AIC criterion for the threshold parameter, even after one year, the shocks on OPEC oil prices persist at $90.8 \%$ i.e. $0.992^{12}$, whereas for the non-OPEC oil prices, they are less persistent at $87.6 \%$. By using the T-sig criterion, the results indicate that even after one year, the shocks on OPEC oil prices persist at $48.2 \%$ i.e. $0.941^{12}$, whereas for the non-OPEC oil prices, they are more persistent at $76.6 \%$.

The permanent component coefficients are well-defined for all the models 1-4, implying the slow convergence of the long-run volatilities to their mean levels, explaining the long-run stability of the process underlying. In contrast, as the sum of the transitory component parameters is negative for both the crude oil prices, there is no half-life defined for either the OPEC or non-OPEC oil prices. This result is due to the high short-run volatility in the transitory variance.

Figures 3a: Conditional and Permanent CGARCH of OPEC and non-OPEC prices
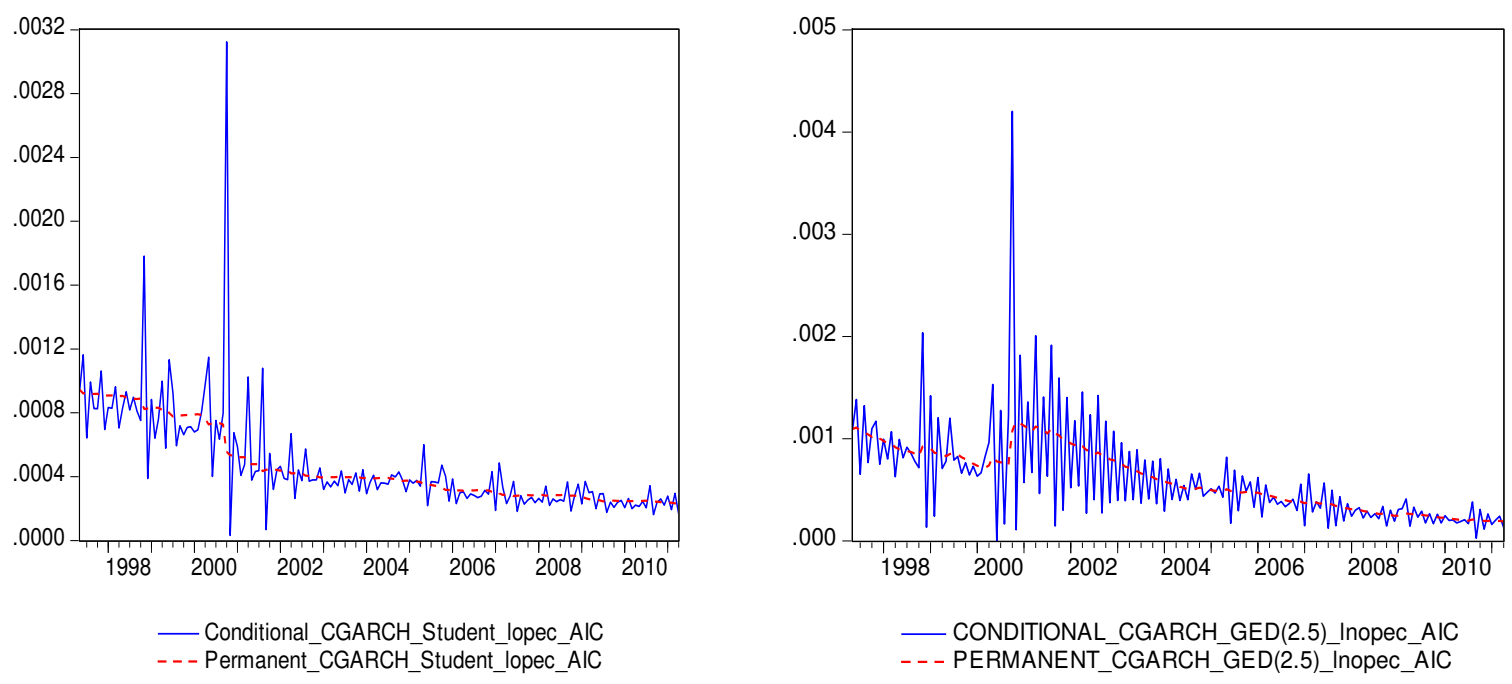
Figures 3b: Conditional and Permanent CGARCH of OPEC and non-OPEC prices
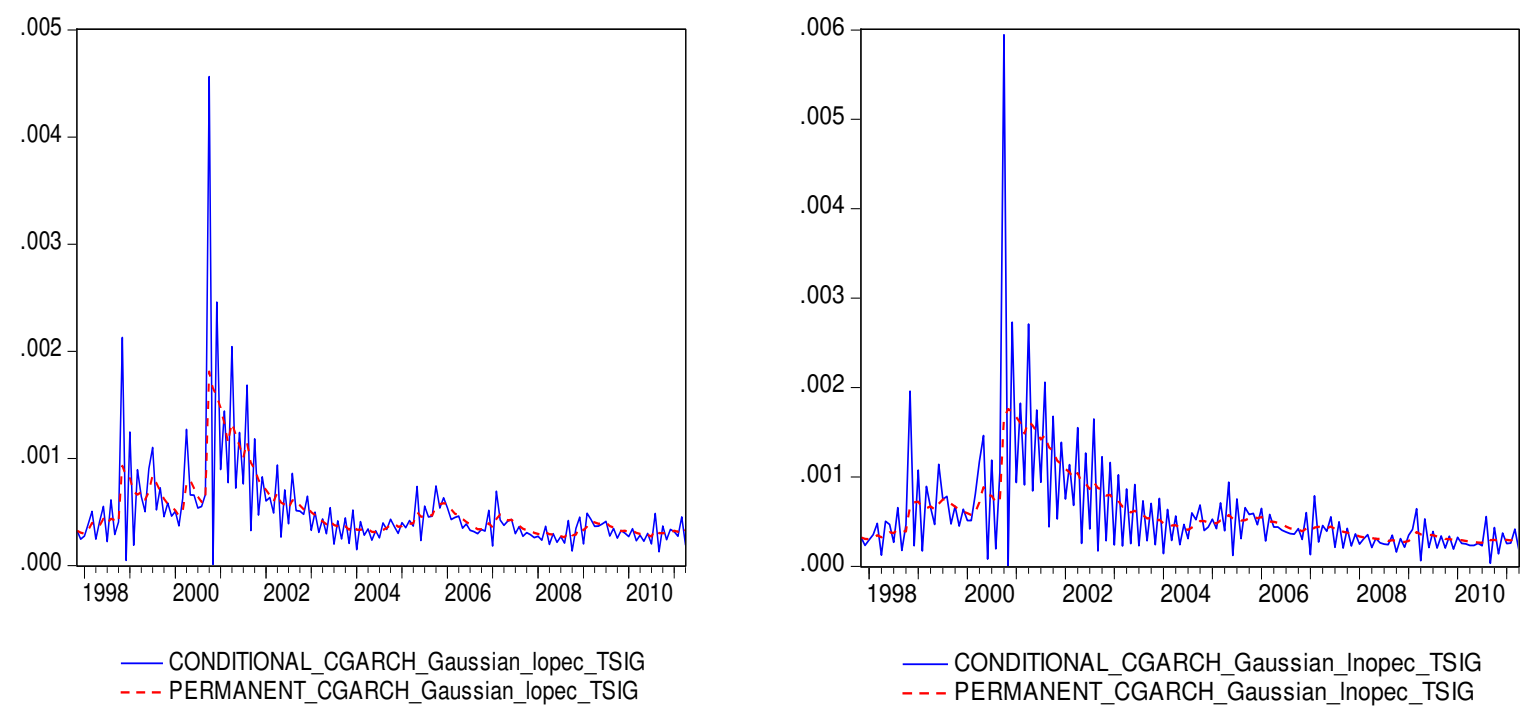

Table 4a: ECM-CGARCH Applied to OPEC and non-OPEC Prices 1997.1-2011.4

\begin{tabular}{|c|c|c|c|c|}
\hline ECM-Threshold & OPEC Model_1 & non-OPEC Model_2 & OPEC Model_3 & non-OPEC Model_4 \\
\hline 1 & $0.0065(2.38)$ & $-0.008(-1.58)$ & $0.0037(1.32)$ & $-0.0079(-1.87)$ \\
$e c t_{t}^{+}$ & $-0.233(-3.34)$ & $-0.839(-3.89)$ & $-0.242(-2.05)$ & $-0.870(-4.14)$ \\
$e c t_{t}^{-}$ & $-0.879(-3.47)$ & $-0.384(-1.87)$ & $-0.839(-4.37)$ & $-0.322(-2.11)$ \\
$\Delta p_{1, t}$ & & $1.043(71.34)$ & & $1.036(68.04)$ \\
$\Delta p_{1, t-1}$ & $0.027(1.93)$ & $-1.142(-0.73)$ & $0.018(1.18)$ & $-0.038(-0.34)$ \\
$\Delta p_{1, t-3}$ & $-0.211(-3.19)$ & $0.265(3.13)$ & $-0.244(-3.24)$ & $0.239(3.01)$ \\
$\Delta p_{2, t}$ & $0.928(73.39)$ & & $0.926(67.55)$ & \\
$\Delta p_{2, t-1}$ & & $0.137(0.69)$ & & $0.03(0.24)$ \\
$\Delta p_{2, t-2}$ & $0.005(0.40)$ & & $0.003(0.21)$ & \\
$\Delta p_{2, t-3}$ & $0.191(3.01)$ & $-0.252(-3.14)$ & $0.217(2.89)$ & $-0.22(-2.72)$ \\
$\hat{\tau}$ & -0.0258 & 0.0215 & -0.0123 & 0.0226 \\
\hline
\end{tabular}

Notes: Model 1 (OPEC_TAR_AIC), Model 2 (non-OPEC_TAR_AIC), Model 3 (OPEC_MTAR_TSIG) and Model 4 (non-OPEC_TAR_TSIG). Using VAR lag selection criteria, we find that the optimal lag is three following the sequential modified LR statistic test, the final prediction error and the AIC. In parentheses, we have the z-statistic. 
Table 4b: Variance Equation CGARCH Applied to OPEC and non-OPEC Prices 1997.1-2011.4

\begin{tabular}{|c|c|c|c|c|}
\hline Variance Equation & OPEC Model_1 & non-OPEC Model_2 & OPEC Model_3 & non-OPEC Model_4 \\
\hline $1_{\omega_{0}}$ & $3.7210^{-5}(0.15)$ & $-1.4510^{-5}(-0.05)$ & $0.0005(3.28)$ & $0.0005(2.61)$ \\
$\left(\varepsilon_{t-1}^{2}-q_{t-1}\right)_{\alpha}$ & $0.198(1.30)$ & $0.204(3.81)$ & $0.216(13.56)$ & $0.227(9.91)$ \\
$\left(\sigma_{t-1}^{2}-q_{t-1}\right)_{\beta}$ & $-0.488(-1.21)$ & $-0.857(-12.91)$ & $-0.747(-7.33)$ & $-0.791(-9.69)$ \\
$\left(q_{t-1}-\omega_{0}\right)_{\rho}$ & $0.992(346.48)$ & $0.989(324.4)$ & $0.941(15.07)$ & $0.949(22.03)$ \\
$\left(\varepsilon_{t-1}^{2}-\sigma_{t-1}^{2}\right)_{\phi}$ & $-0.013(-0.83)$ & $0.0203(0.89)$ & $0.094(1.53)$ & $0.082(1.42)$ \\
AIC & -4.786 & -4.667 & -4.759 & -4.660 \\
SSR & 0.024 & 0.026 & 0.023 & 0.025 \\
$l l$ & 416 & 405 & 399 & 390 \\
\hline LM-ARCH Test & $0.947(3)$ & $0.578(5)$ & $0.930(2)$ & $0.951(2)$ \\
\hline Ljung-Box Test & $11.64[0.47]$ & $15.94[0.19]$ & $17.64[0.13]$ & $16.77[0.16]$ \\
\hline Wald Test for $\rho=1$ & $7.8918[0.005]$ & $10.2079[0.002]$ & $0.8903[0.35]$ & $1.3823[0.24]$ \\
\hline
\end{tabular}

Notes: The z-statistics are in parentheses. The LM-ARCH statistic tests of no ARCH effects in the residuals of the estimated equation, the number of lags is in parentheses. The Ljung-Box statistic tests of no serial correlation in the residuals. The Wald test is running to test the unit value of the persistence parameter $\rho$ using $\chi^{2}$ statistic. The $\mathrm{p}$-values are in brackets.

A negative (positive) ect $\mathrm{t}_{\mathrm{t}-1}$ signals an upward (downward) adjustment of the price starting from the next period and from the deviations to the long run equilibrium (Enders \& Siklos 2000). A small (high) value of the long run coefficient $\mu_{\mathrm{i}}$ indicates that the error correction term of the oil price process is weakly (strongly) exogenous with respect to the long run relationship between OPEC and non-OPEC prices. The adjustment of OPEC price process in relation to the positive discrepancies in the long run equilibrium shows the appropriate negative sign, and the slow adjustment indicates that the OPEC organization does not prefer modest oil prices. In contrast, a rapid adjustment of non-OPEC price process in relation to the positive discrepancies in the long run equilibrium signifies a preference of modest oil prices after they increase. This speed difference between OPEC and non-OPEC price processes is an evidence of competitive behavior between OPEC and non-OPEC countries. The OPEC producers could not drive down (up) the crude oil prices for all participants in the market. The market participants, who 
assume the OPEC actions, caused the price fluctuations (Hammoudeh 1997). However, our results show that non-OPEC participants do not follow the OPEC strategies. The asymmetric adjustment provides evidence that the market participants sometimes misuse their market power in oil price determination.

The point estimates for $e c t_{t-1}^{-}$, i.e., the undervaluation, are in absolute value and are somewhat high between 0.73 and 0.87 in the model 1,3 and 4 , suggesting that the deviations between an increase in the long run and the plausible crude oil prices are eliminated rather quickly. In contrast, the point estimates for $e c t_{t-1}^{+}$, i.e., the overvaluation, are reported in absolute value and are on the low side between 0.23 and 0.34. In these cases, the asymmetry is largely driven by a strong response to negative shocks. The negative discrepancies of the OPEC prices from the long run equilibrium are eliminated quite quickly in comparison to the non-OPEC prices. This result confirms that the non-OPEC countries set modest oil prices and are more sensible to overvaluation.

Using the T-significance criterion, the results of Models 3 and 4 indicate that there are indeed two types of asymmetric long run effects: the point estimates for the error correction term are negative for the OPEC prices, but positive for the non-OPEC prices. Unexpectedly, the LR changes in OPEC crude oil prices are accompanied by LR changes in non-OPEC prices in the opposite direction. Therefore, when the crude oil prices tend to be overvalued, an asymmetric phenomenon occurs with an expected negative sign of $\mu_{2}$, which indicates that OPEC prices will revert to the intrinsic LR equilibrium and therefore have a stabilizing effect, whilst the non-OPEC has an unexpected positive sign of $\mu_{2}$, which indicates that the prices will increase, but will revert finally to the LR equilibrium. The result of the non-OPEC price change can be explained by their excessive aversion behavior.

The non-OPEC (OPEC) prices move upward in the short run, if they are undervalued relative to the OPEC (non-OPEC) crude oil prices, which would influence the OPEC prices from Model 1 and 3 (Model 2 and 4). The crude oil prices of non-OPEC countries would adjust upwards at a slower rate to correct the imbalance with the OPEC crude oil prices than would the OPEC prices if they were to adjust upwards to correct the imbalance. 
The appearance of imperfect competition, due to many causes, implies an inefficient market. The subdued adjustment of positive discrepancies to the long run equilibrium may occur because OPEC countries want to control the high prices of oil and try to sporadically retain the oil prices around equilibrium level. The non-OPEC countries also provide trivial support in this respect. In the short run, there is evidence of a causal flow of changes of contemporary oil price from non-OPEC to OPEC countries and vice versa, with many discernible feedback relationships. The OPEC quota agreements contribute to this short run price fluctuation. As a result, the price of oil in one group affects the other group's price of oil. In particular, the $\mathcal{F}$-statistics corresponding to causality reveal that prices of each group, OPEC and non-OPEC, affect the movements in the other group's current price rate.

\section{Conclusion}

The empirical analysis of this paper examined the dynamics of OPEC and non-OPEC oil prices using the TAR-Error Correction-CGARCH model, which leads to a parsimonious representation of some stylized features, for the period January 1997 to April 2011. Based on the adjustment rate of the permanent component errors, the estimated TAR-ECM-CGARCH showed evidence of long run volatility in the variance and asymmetric effects of negative and positive shocks. Using the AIC criterion for the threshold parameter, after one year, $90.8 \%$ of the effects of the shocks on OPEC oil prices persist, whereas for the non-OPEC oil prices, less than $87.6 \%$ of the effects of the shocks persist. By using the T-significance criterion, this result indicates that even after one year, the impact of shocks on the OPEC oil prices will persist at $48.2 \%$, whereas for the non-OPEC oil prices, the impact persists at a higher rate than $76.6 \%$. These results show that the conditional volatility has a long run memory feature, which supports the long run memory for oil price volatility.

The slow OPEC adjustment to positive discrepancies in the long run equilibrium shows that OPEC organization does not prefer modest oil prices, while a rapid adjustment in the non-OPEC process signifies a preference of modest oil prices after oil price increases. These differences in speeds between 
OPEC and non-OPEC price adjustments imply that there is evidence of a competitive behavior and different profit and pricing strategies between OPEC and non-OPEC countries. The OPEC producers could not drive down (up) crude oil market prices. Market traders and speculators, who assume the OPEC actions, cause the price fluctuations. Additionally, our results show that the non-OPEC participants do not follow the OPEC strategies. In other words, this implies that OPEC is not the leader in the world crude oil market. The future work has to use the asymmetric multivariate GARCH models to better understand the permanent and transitory components in the crude oil market prices.

\section{References}

1. Adelman, MA., 1962. Natural Gas and the World Petroleum Market. The Journal of Industrial Economics 10, 76-112.

2. Alexander C. and E. Lazar, 2006. Normal Mixture $\operatorname{GARCH}(1,1)$ : Applications to exchange rate modeling. Journal of Applied Econometrics 21: 307 - 336. DOI: 10.1002/jae.849.

3. Angrist, J., Graddy, K. and Imbens, GW., 2000. The Interpretation of Instrumental Variables Estimators in Simultaneous Equations Models with an Application to the Demand for Fish. The Review of Economic Studies 67 (3), 499-527.

4. Balke, NS., Brown, SPA., Yucel, MK., 1998. Gasoline and crude oil prices: an asymmetric relationship? Federal Reserve Bank of Dallas Economic Review, First Quarter, 2-11.

5. Berndt, ER., and Wood, DO., 1975. Technology, prices, and the derived demand for energy. The Review of Economics and Statistics 57(3), 259-268.

6. Bekiros, SD., and Diks CGH., 2008. The relationship between crude oil spot and futures prices: Cointegration, linear and nonlinear causality. Energy Economics 30(5), 2673-2685.

7. Bollerslev T. and R.F. Engle, 1993. Common Persistence in Conditional Variances. Econometrica 61, 166-187.

8. Borenstein, S., Cameron, AC., Gilbert, R., 1997. Do gasoline prices respond asymmetrically to crude oil price changes? Quarterly Journal of Economics 112, 305-339.

9. Chan , KS., 1993. Consistency and limiting distributions of the least Squares estimator of a Threshold Autoregressive Model. The Annals of Statistics 21, 520-533.

10. Chen, Li-Hsueh, T., Miles Finney, Lai, Kon S., 2005. A threshold cointegration analysis of asymmetric price transmission from crude oil to gasoline prices. Economic Letters 89(2), 233-239. 
11. De Santis, RA., 2003. Crude oil price fluctuations and Saudi Arabia's behavior. Energy Economics 25(2), 155-173.

12. Diebold F.X. and J.A. Lopez, 1995. Modeling Volatility Dynamics. Macro-econometrics, Recent Economic Thought Series Volume 46:427-472.

13. Enders, W., Granger C., 1998. Unit root tests and asymmetric test with an example using the term structure of interest rate, Journal of Business and Economic Statistics 16, 304-311.

14. Enders, W., Siklos, PL., 2001. Cointegration and threshold adjustment. Journal of Business and Economic Statistics 19, 166-176.

15. Energy Information Administration (EIA), 1999. Prices Changes in the Gasoline Market: Are Midwestern gasoline prices downward sticky? US Department of Energy, Washington, DC.

16. Engle R.F. and A.J. Patton, 2000. What good is a volatility model? Quantitative Finance 1(2), 237245.

17. Engle, R. and G. Lee, 1999. A Long-Run and Short-Run Component Model of Stock Return Volatility, in Cointegration, Causality and Forecasting. Edited by R. Engle and H. White, Oxford University Press.

18. Engle R.F. and G. Gonzalez-Rivera, 1991. Semi-parametric ARCH Models. Journal of Business \& Economic Statistics 9(4): 345-359.

19. Engle, R. and Granger, C.W.J. 1987. "Co-integration and error-correction: Representation, estimation, and testing." Econometrica 35: 315-329.

20. Ewing, B., Hammoudeh, S and Thompson, 2006. Examining Asymmetric Behavior in US Petroleum Futures and Spot Prices. The Energy Journal 27(3), 9-23.

21. Gately, D., 1984. A ten-year retrospective: OPEC and the world oil market. Journal of Economic Literature 22(3), 1100-1114.

22. Gately, D., 1993. The Imperfect Price-reversibility of World Oil Demand. The Energy Journal 14(4), 163-182.

23. Gately, D., and Huntington, HG., 2002. The Asymmetric Effects of Changes in Price and Income on Energy and Oil Demand. The Energy Journal 23 (1), 19-55.

24. Godby, R., Lintner, AM., Stengos, T., Wandschneider, B., 2000. Testing for Asymmetric Pricing in the Canadian Retail Gasoline Market. Energy Economics 22, 349-368.

25. Goldberger, AS., 1991. A course in econometrics. Harvard University Press, Cambridge, MA.

26. Gospodinov, N., 2008. Asymptotic and bootstrap tests for linearity in a TAR-GARCH(1,1) model with a unit root. Journal of Econometrics 146(1), 146-161.

27. Griffin, JM., 1985. OPEC behavior: A test of alternative hypotheses. The American Economic Review 75 (5), 954-963. 
28. Hamilton, JD., 2008. Understanding Crude Oil Prices. National Bureau of Economic Research, Working Paper number 14492.

29. Hammoudeh, S., 1997. Oil Pricing Policies in a Target Zone Model. Research in Human Capital and Development, Vol. 11-B: 497-513.

30. Hammoudeh, S., Chen, LH., and Fattouh B., 2010. Asymmetric Adjustments in Oil and Metals Markets. The Energy Journal 31(4): 183-203.

31. Hatanaka M., 1996. Time-Series-Based Econometrics: Unit Roots and Co-integrations (Advanced Texts in Econometrics). Oxford University Press. Reprinted 2003. ISBN-13: 978-0198773535.

32. Hausman, JA., 1975. Project independence report: an appraisal of U.S. energy needs up to 1985. The Bell Journal of Economics 6 (2), 517-551.

33. Holton, Glyn A., 2014. Value-at-Risk: Theory and Practice, 2nd ed. e-book at http://value-at-risk.net.

34. Horvath \& Watson, 1995. Testing for Cointegration when some of the Cointegrating Vectors are Prespecified. Econometric Theory 11, 984-1014.

35. Jones, Clifton T., 1990. OPEC Behavior under Falling Prices: Implications for Cartel Stability, The Energy Journal 11(3), 117-130.

36. Kang, SH., Kang, SM., and Yoon SM., 2009. Forecasting volatility of crude oil markets. Energy Economics 31(1), 119-125.

37. Kennedy, M., 1974. An Economic Model of the World Oil Market. The Bell Journal of Economics and Management 5 (2), 540-577.

38. Lin, CYC., 2009. An Empirical Dynamic Model of OPEC and non-OPEC. Presented in International Association for Energy Economics North American conference, Houston, September.

39. Li., Raymond, 2010. The Role of OPEC in the World Oil Market. International Journal of Business and Economics 9, (1), 83-85.

40. Manski, CF., 1995. Identification Problems in the Social Sciences. Harvard University Press, Cambridge, MA.

41. Mohammadi, H., and Su, L., 2010. International evidence on crude oil price dynamics: Applications of ARIMA-GARCH models. Energy Economics 32(5), 1001-1008.

42. Ng, S., Perron, P., 2001. Lag Length Selection and the Construction of Unit Root Test with Good Size and Power. Econometrica 69, 1519-1554.

43. Nordhaus, WD., 1980. Oil and Economic Performance in Industrial Countries. Brookings Papers on Economic Activity 2, 341-399.

44. Perron, P., Rodriguez, G., 2001.Residual based tests for cointegration with GLS detrended data, Manuscript, Boston University. 
45. Petrucelli, J. and S. Woolford (1984). A Threshold AR(1) Model. Journal of Applied Probability 21, $270-86$.

46. Poon S.H., Hyung, N. and C.W.J. Granger, 2006. A Source of Long Memory in Volatility. Available at SSRN: http://ssrn.com/abstract=904582 or http://dx.doi.org/10.2139/ssrn.904582.

47. Ray, BK. and RS. Tsay, 2000. Long-range dependence in daily stock volatilities. Journal of Business \& Economic Statistics 18: 254-262.

48. Stock J.H. and M.W. Watson, 1988. Testing for Common Trends. Journal of the American Statistical Association 83(404), 1097-1107.

49. Tong, H., 1990. Non Linear Time Series: A Dynamical Approach. Oxford, UK: OUP. 


\section{Appendices}

Figures 1: OPEC and non-OPEC prices
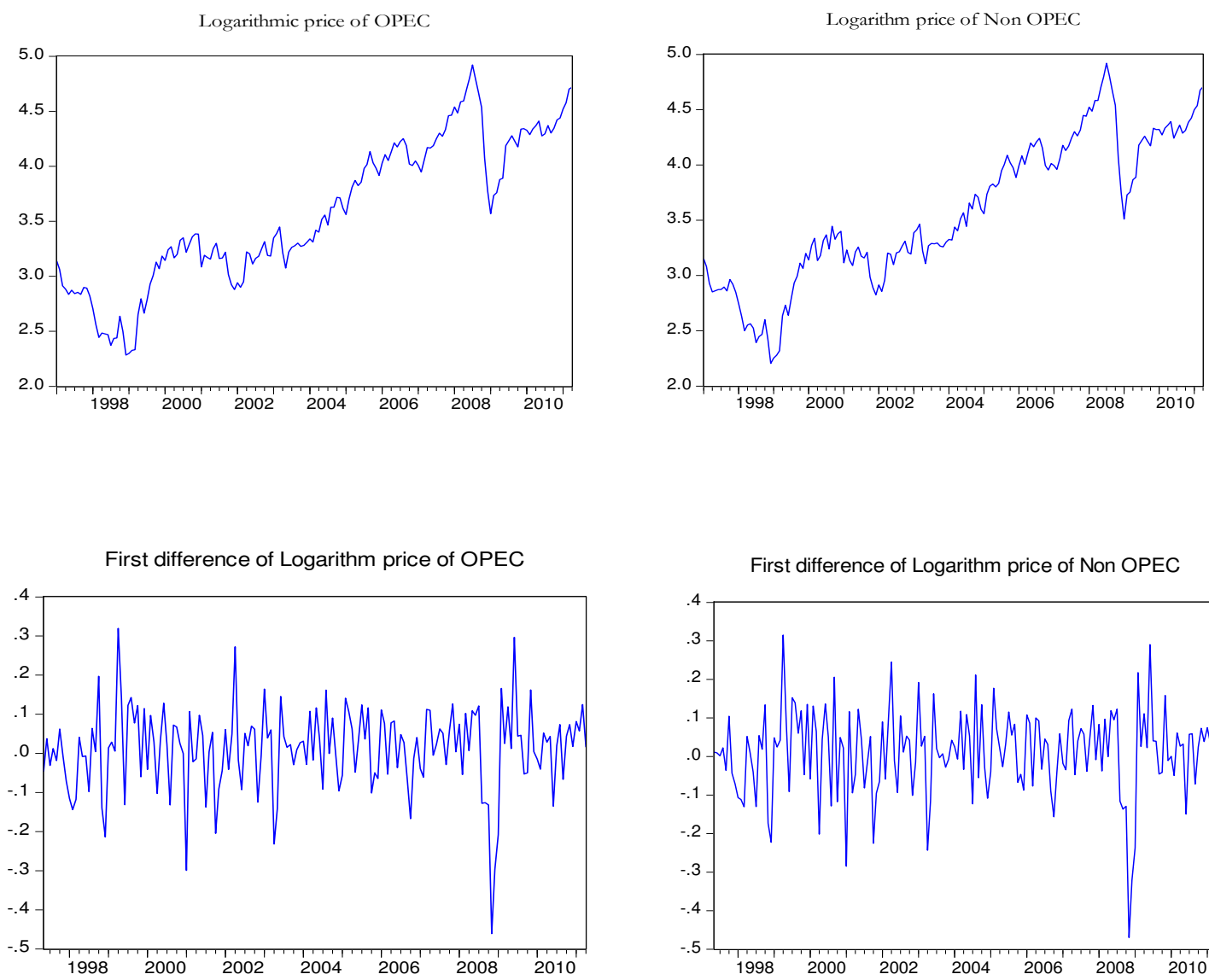

First difference of Logarithm price of Non OPEC

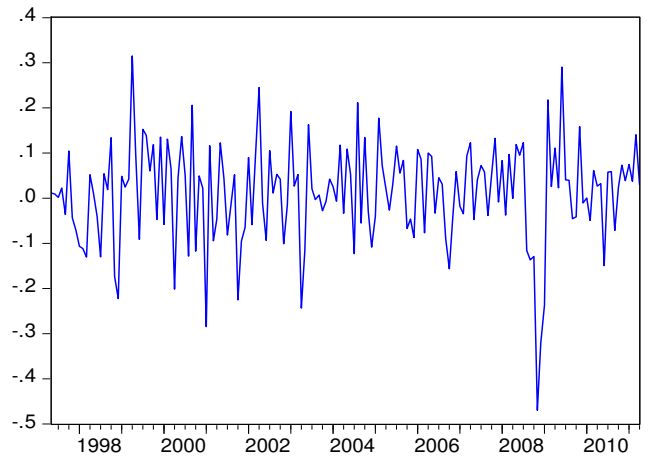

Figures 2: Persistence shocks over month's horizon on OPEC and non-OPEC prices
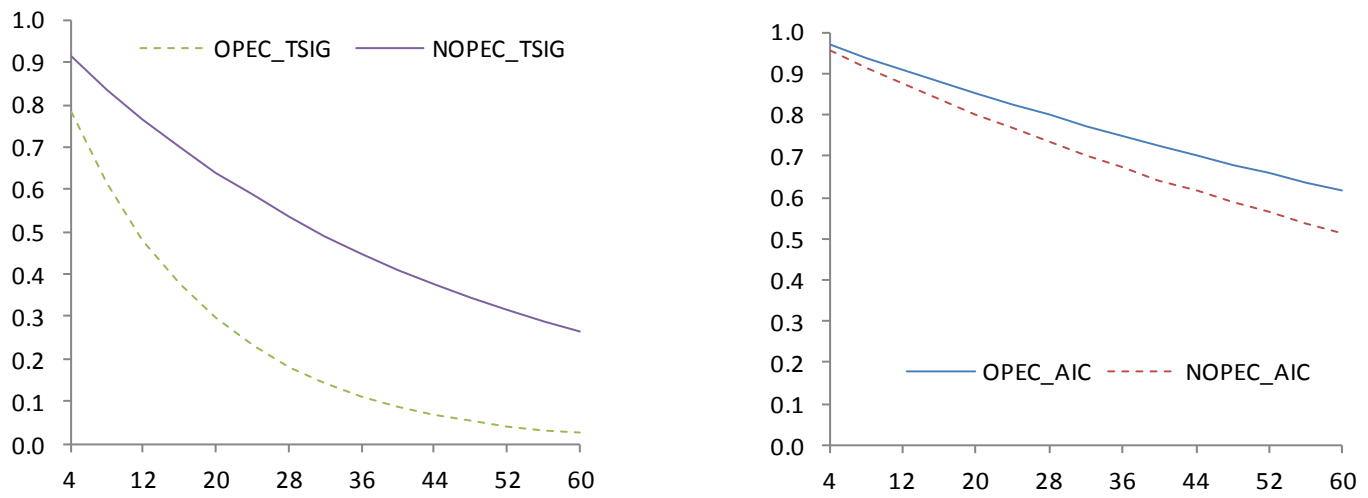
Table A: World Oil Supply and Demand Barrels (Per Million Day)

\begin{tabular}{|c|c|c|c|c|c|}
\hline Year & 2005 & 2006 & 2007 & 2008 & 2009 \\
\hline OPEC Supply to World market & 34.7 & 35.4 & 34.6 & 35.6 & 33.3 \\
\hline non-OPEC Excess Demand-Supply & 34.1 & 34.6 & 35.6 & 35.1 & 33.0 \\
\hline
\end{tabular}

Source: Oil Market Report, Annual Statistical Supplement, I.E.A. 2010

Table B: World Oil Production: OPEC and non-OPEC (\%)

\begin{tabular}{|c|c|c|c|c|c|}
\hline Year & 2005 & 2006 & 2007 & 2008 & 2009 \\
\hline OPEC & 40.50 & 40.20 & 41.98 & 41.25 & 39.32 \\
\hline non-OPEC & 59.50 & 59.80 & 58.02 & 58.75 & 60.68 \\
\hline
\end{tabular}

Source: Annual Report, S.A.M.A. 2010

\section{End Notes:}

\footnotetext{
'As demonstrated by Sichel (1993), a negative "deepness" (i.e. $\left|\rho_{1}\right|<\left|\rho_{2}\right|$ ) of $\hat{\varepsilon}_{t}$ implies that increases tend to persist, whereas decreases tend to revert quickly towards equilibrium.

ii In the EG's test: one sided (lower tail) test of the null hypothesis that the variables are not co integrated; at the 1, 5, and 10 per cent level critical value equal $-4.02,-3.40$ and -3.09 , respectively (Rapach \& Weber 2004). In the PR's test: one sided (lower-tail) test of the null hypothesis that the variables are not co-integrated; at the 1, 5, and 10 per cent level critical value equal $-3.33,-2.76$ and -2.47 , respectively (Perron \& Rodriguez 2001).

iii The double $*$ indicates significance-level at $1 \%$. The values corresponding to $\Phi$ are compared with $\Phi$ tables computed by Enders and Siklos (2001). The numbers in parentheses in the third and fourth columns denote t-values.

iv The heteroscedasticity test indicates that the ARCH effect is largely reduced using ECM-TAR-CGARCH (see last row of Table 4), this improvement of regressions is explained by the diminution of Skewness and Kurtosis coefficients.
} 